\title{
CARDIOGRAPHIC STUDIES IN SEVERE PULMONARY EMPHYSEMA
}

\author{
BY \\ J. P. D. MOUNSEY, L. W. RITZMANN * AND N. J. SELVERSTONE $\dagger$ \\ From the Department of Medicine, Postgraduate Medical School of London, W.12 \\ Received December 28, 1951
}

The introduction of cardiac catheterization has offered the possibility of a further aid to the early diagnosis of emphysema heart disease by direct measurement of right ventricular pressures. In this paper cardiographic findings have been related to right ventricular pressures in severe pulmonary emphysema. Similar studies have been carried out by Johnson et al. (1950) and Kilpatrick (1951).

\section{Material AND MethodS}

All of the sixteen cases were diagnosed clinically as chronic bronchitis and emphysema, and suspected of having heart disease secondary to their emphysema. In every case respiratory studies were carried out confirming the presence of severe emphysema. Eight of the patients had systemic hypertension in addition to chronic bronchitis and emphysema but none was considered to have evidence of left ventricular failure.

Clinically, the patients fell into three main groups at the time of cardiac catheterization: those who had never been in heart failure, those in congestive failure, and those recovering from congestive failure. Congestive failure was considered to be present when the jugular venous pressure was found to be raised, whether or not œdema was present. Unless œdema had developed, it was difficult to fix the time of onset of cardiac failure adequately from the clinical history, since symptoms due to emphysema heart disease were gradually superimposed upon those of pulmonary emphysema.

Measurements of right ventricular pressure were recorded by strain gauge manometry, as described previously by Bayliss et al. (1950).

Cardiographic exploration included standard leads, augmented unipolar limb leads, and at least four chest leads V5, V3, V1 and V4R. The technique used did not permit measurement of time intervals on the tracings more closely than to an hundredth of a second.

The cardiograms were recorded as far as possible within a few days of the date of catheterization. In eight cases, however, a longer interval separated the two investigations. This interval was a week in five cases and between two to three weeks in three. It was not considered that this invalidated the correlation of right ventricular pressures with the cardiogram in these cases, since in those patients in whom more frequent serial cardiograms were taken no significant cardiographic changes were noticed over a similar period of time, even under the stress of an episode of congestive cardiac failure.

The cardiographic criteria for the diagnosis of right ventricular hypertrophy were based on the findings of Wilson et al. (1947), later amplified by Myers et al. (1948). Myers described three patterns in right ventricular hypertrophy. The first pattern, which he considered diagnostic of right ventricular hypertrophy, showed (1) a prolonged time interval between the beginning of the QRS complex and the onset of the intrinsicoid deflection in V1, generally between $0.03-0.05$ second,

* Research Fellow of the American Heart Association.

+ Moseley Travelling Fellow in Medicine, Harvard University. 
which was greater than that in V5 and V6; (2) a total duration of the QRS complex less than 0.12 second; (3) a tendency to a small $\mathrm{Q}$ wave in V1; (4) a reversal of the ratio of amplitudes of the $R$ and $S$ waves in V1 and V6, characterized by an abnormally large $R$ in proportion to $S$ in $V 1$, and a prominent $\mathrm{S}$ in $\mathrm{V} 6$; (5) a tendency to inversion of $\mathrm{T}$ in $\mathrm{V} 1$ and to an upright $\mathrm{T}$ in V6; and (6) absence of notching of $R$ in V1 except where preceded by a $Q$ wave. In the second pattern of Myers the cardiographic picture just described in lead V1 was confined to V3R and was not seen in V1. Myers' third pattern, in which lead aVR alone gave evidence of right ventricular hypertrophy, was not met in our series. We have used leads V5 and V4R routinely instead of V6 and $V 3 R$ respectively.

An RSR' pattern was met in our series in which (1) the total duration of the QRS complex did not exceed 0.12 second; (2) the time interval from the beginning of the QRS complex to the peak of the final $\mathrm{R}$ wave in $\mathrm{V} 1$ was between $0.05-0.07$ second; (3) $\mathrm{Q}$ waves were absent from leads on the right side of the præcordium; and (4) notched or double-peaked $\mathrm{R}$ waves were present in leads from the right side of the præcordium, while in leads from the left side there tended to be prominent $\mathrm{S}$ waves.

The diagnosis of complete right bundle branch block was made when (1) the total duration of the QRS complex was $0 \cdot 12$ second or longer; (2) the peak of the final $\mathrm{R}$ wave in lead V1 was later in time than the peak of the $\mathrm{R}$ wave in V5; and (3) in leads from the right side of the præcordium $\mathrm{R}$ waves were prominent, coarsely notched, or double-peaked, and $\mathrm{Q}$ waves were absent.

\section{RESULTS}

There were thirteen men and three women in the series, the average age being 50.9 years. In all cases the residual air expressed as a percentage of total lung volume was greatly raised, the average value being 67 per cent (normal range 16 to 40 per cent). Half of the patients had systemic hypertension in addition to pulmonary emphysema, our upper limits of normal systemic blood pressure being 150 systolic and $90 \mathrm{~mm}$. $\mathrm{Hg}$ diastolic.

Right Ventricular Pressures. On cardiac catheterization, in the absence of congestive failure, the right ventricular systolic pressure was found to be normal or only moderately raised. In the presence of failure, however, pressures were significantly raised in every case. As patients recovered from failure, restoration of their right ventricular pressures towards normal occurred. The pulmonary hypertension seen in heart failure in emphysema therefore was reversible, a finding in agreement with previous studies by Borden et al. (1950), Ferrer et al. (1950), and Harvey et al. (1951). Details of right ventricular pressure records are given in Table I, where it will be seen that eleven cases had raised resting systolic pressures in the absence of heart failure, the upper limit of normal being taken as $30 \mathrm{~mm}$. $\mathrm{Hg}$.

Cardiograms. On analysis of the cardiograms the cardiographic picture of right ventricular hypertrophy was found in two of the sixteen cases. Nine patients showed no cardiographic evidence of right ventricular hypertrophy, and one had complete right bundle branch block. Four showed an RSR $^{\prime}$ pattern in right præcordial leads, which was persistent on serial graphs over a period of at least six weeks.

In five cases in whom two sets of right ventricular pressures were measured, both in failure and on recovery from failure, the analysis of only one cardiogram is shown for each patient, since no significant differences were noted in corresponding serial cardiograms.

Effect of Associated Systemic Hypertension on the Cardiogram. Associated systemic hypertension appeared to modify the cardiographic pattern in left chest leads. In the series as a whole small $\mathrm{R}$ and large $\mathrm{S}$ waves were usually seen in these leads, irrespective of the presence or absence of evidence of right ventricular hypertrophy in right chest leads. It was thought that this was due to the vertical position of the heart in emphysema. In the eight cases where there was associated systemic hypertension, a larger $\mathrm{R}$ and smaller $\mathrm{S}$ wave was seen in left chest leads, but in no case was the cardiographic picture of left ventricular hypertrophy present. 


\begin{tabular}{|c|c|c|c|c|c|c|c|}
\hline \multirow{7}{*}{ 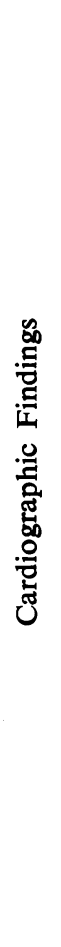 } & & 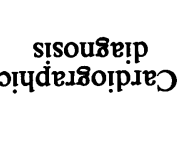 & 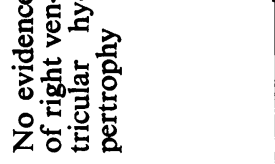 & 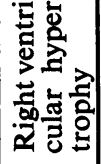 & & 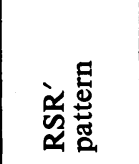 & 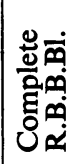 \\
\hline & \multirow{2}{*}{ 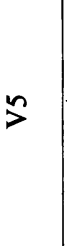 } & $\begin{array}{l}\text { oṇey } \\
\text { S/y }\end{array}$ & 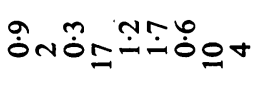 & Nö & & $m b \stackrel{-0}{0}$ & $\theta$ \\
\hline & & 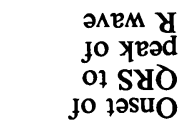 & 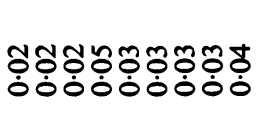 & 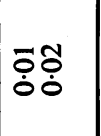 & & 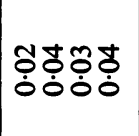 & 菅 \\
\hline & & $\begin{array}{l}\text { onpey } \\
\text { S/y }\end{array}$ & 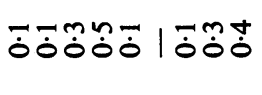 & mN & o!̣ey $\mathbf{S} /, \mathbf{y}$ & | 1 | & $\stackrel{n}{\dot{q}}$ \\
\hline & $>$ & 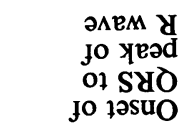 & 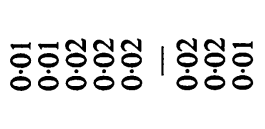 & 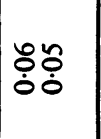 & 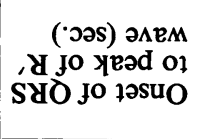 & | | & 齐 \\
\hline & \multirow{2}{*}{$\frac{\mathfrak{q}}{>}$} & ọpey $\mathbf{S} / \mathbf{y}$ & $\overrightarrow{000} \mid \overrightarrow{0}$ & $m \stackrel{n}{-}$ & o!̣ey S/,y & $\overrightarrow{0}-\forall n$ & $\theta$ \\
\hline & & 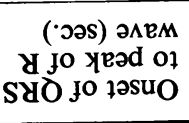 & 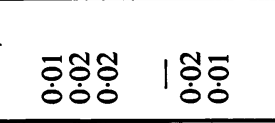 & 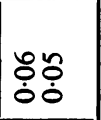 & 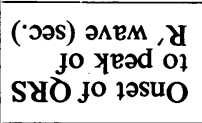 & 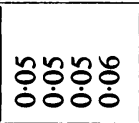 & 䎹 \\
\hline \multirow{8}{*}{ 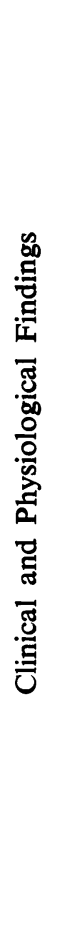 } & \multirow{3}{*}{ 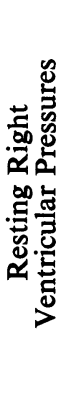 } & 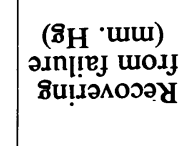 & 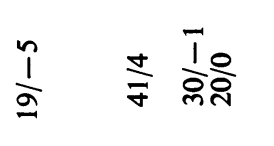 & $\frac{n}{2}$ & & $\frac{p}{\frac{m}{a}}$ & $\frac{d}{\frac{1}{2}}$ \\
\hline & & 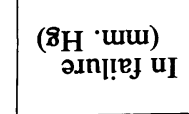 & $\frac{\infty}{\tilde{\gamma}} \quad \frac{\nabla}{\hat{\sigma}}$ & $\sum_{\infty}^{\infty}$ & & $\frac{a}{i}$ & \\
\hline & & 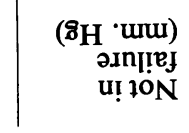 & 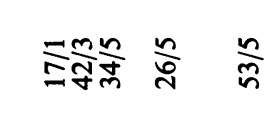 & & & $\frac{\bar{m}}{\frac{1}{3}}$ & \\
\hline & \multicolumn{2}{|c|}{ 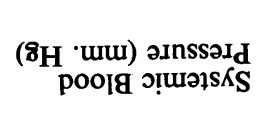 } & 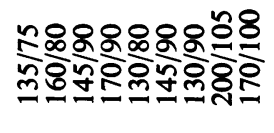 & 용요 & & 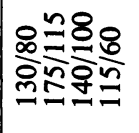 & 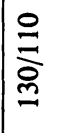 \\
\hline & \multicolumn{2}{|c|}{ 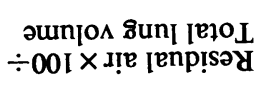 } & ஃைஃலூロ & 뉸 & & মลㅇํำ & 8 \\
\hline & \multicolumn{2}{|r|}{ xəS } & $\Sigma \Sigma \Sigma \Sigma \Sigma \Sigma \Sigma \Sigma \Sigma$ & ๘ & & $\sum \amalg \Sigma \Sigma$ & $\Sigma$ \\
\hline & \multicolumn{2}{|r|}{ ว8ิV } & 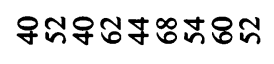 & テチ & & กู융ำ & $\approx$ \\
\hline & \multicolumn{2}{|r|}{ 'ON OSED } & 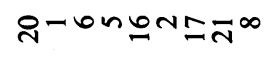 & গี & & $\operatorname{Tann}$ & $\infty$ \\
\hline
\end{tabular}


Autopsy findings. Autopsy confirmation of emphysema heart disease was obtained in Case 16. A grossly hypertrophied right ventricle was found, the anterior wall of the outflow tract at a point $2 \mathrm{~cm}$. below the pulmonary valves, measuring $10 \mathrm{~mm}$. in thickness. The lungs showed evidence of chronic bronchitis and vesicular emphysema. The cardiogram is illustrated in Fig. 1, the first

25.5.50

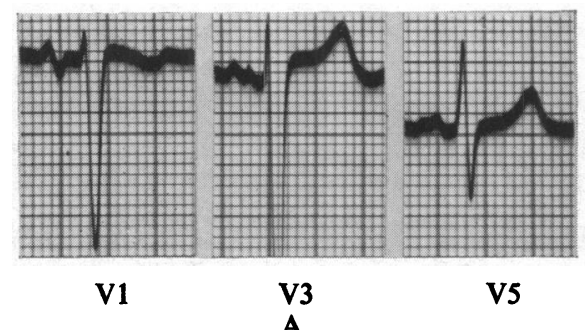

20.3.51

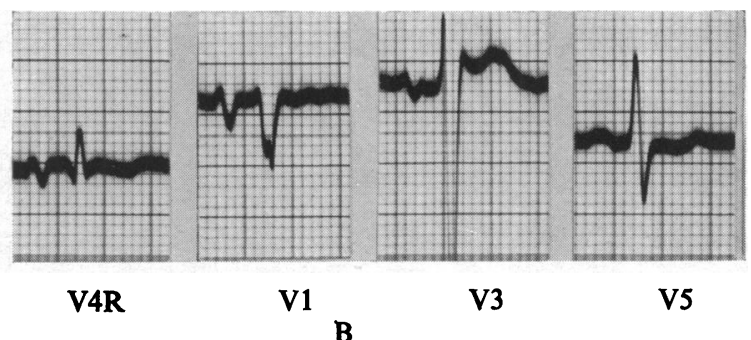

FIG. 1.-Selected chest lead cardiograms of case 16. (A) At the time of cardiac catheterization. Right ventricular pressure raised $(41 / 4 \mathrm{~mm}$. $\mathrm{Hg}$ ). No cardiographic evidence of right ventricular hypertrophy. (B) Two months before death. At autopsy gross right ventricular hypertrophy. Cardiogram shows $Q R$ pattern of right ventricular hypertrophy in V4R.

tracing (A) being at the time of cardiac catheterization, when cardiographic evidence of right ventricular hypertrophy was absent. The second tracing (B) was taken two months before death and shows evidence of right ventricular hypertrophy confined to lead V4R.

The Embryonic R Wave, the RSR' Pattern, and Right Ventricular Hypertrophy

In Fig. 2, the QRS patterns found in leads V1 and V4R of the sixteen patients at the time of catheterization are illustrated diagrammatically. They have been divided into eight different patterns. It will be seen that there is an apparent progression in the height of the secondary $R$
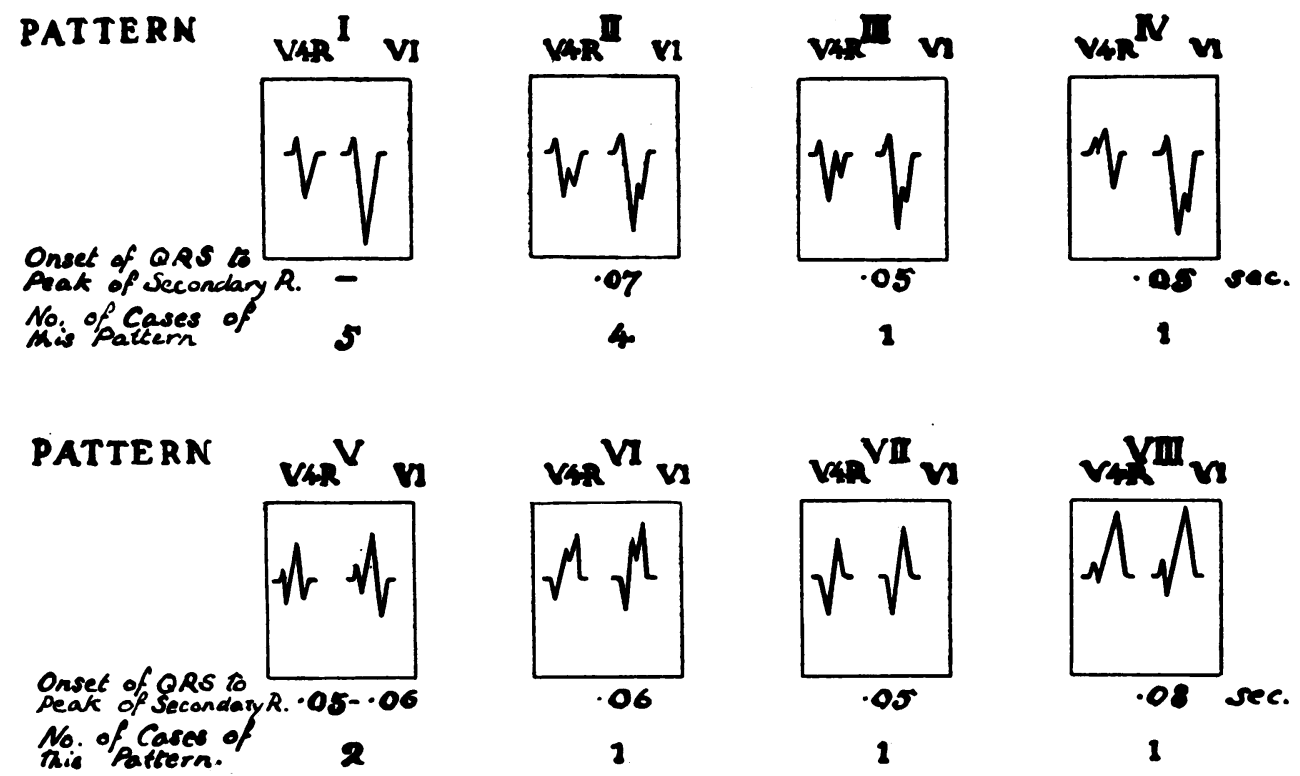

FIG. 2.-Diagram illustrating QRS patterns in V1 and V4R seen in sixteen cases of severe pulmonary emphysema. There appears to be a progressive increase in size of the secondary $R$ wave in patterns II to VII, starting with an embryonic $\mathbf{R}$ wave in pattern II and ending with the secondary $\mathbf{R}$ wave of the RSR' pattern in patterns III, IV and $V$ and with the final $R$ wave of right ventricular hypertrophy in patterns VI and VII. Pattern VIII shows complete right bundle branch block. 
wave, starting from a small embryonic $R$ wave * in pattern II and ending with a secondary $R$ wave in patterns III, IV, and V (RSR' complex) and with a final $R$ wave in patterns VI and VII (right ventricular hypertrophy). Pattern VIII is an example of complete right bundle branch block. The timing of the embryonic $R$ waves lay between $0.05-0.07$ second after the beginning of the QRS complex.

In an effort to determine the significance of embryonic $R$ waves in lead V1 and V4R, cardiograms were recorded in a series of 30 healthy men, aged between 20 and 40 . An embryonic $R$ wave in V1 and V4R was seen in fourteen of the thirty cases and occurred between 0.05 and 0.07 second after the onset of the QRS complex in thirteen and at 0.04 second in one. It was therefore concluded that the occurrence of an embryonic $R$ wave between 0.04 and 0.07 second after the start of the QRS complex in V1 and V4R may be within normal limits.

We thought it possible that the embryonic $\mathrm{R}$ wave in normal hearts might, with the development of right ventricular hypertrophy, sometimes increase in voltage until it became the secondary $R$ wave of the $\mathrm{RSR}^{\prime}$ pattern or the $\mathrm{R}$ wave of right ventricular hypertrophy. With this in view, serial cardiograms of three patients over a period of up to $2 \frac{1}{2}$ years were examined, and it seemed that they did, in fact, lend support to this theory. Two cases were of the RSR' pattern (Fig. 3 and 4)

\subsubsection{9}

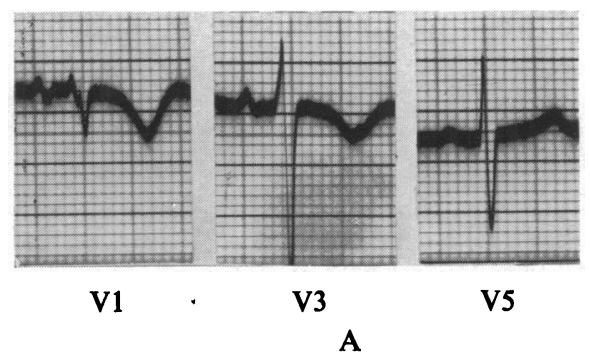

\subsubsection{1}

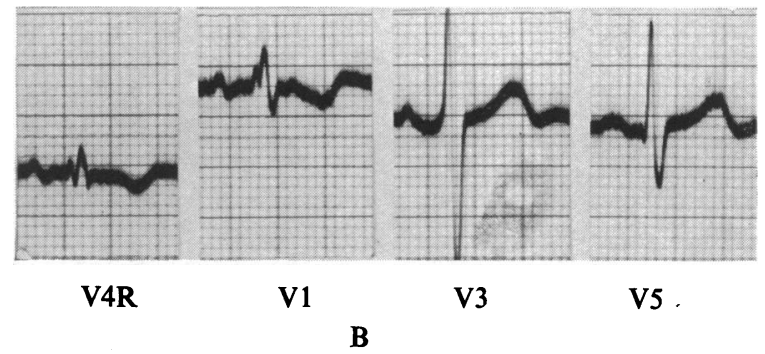

Fig. 3.- Selected chest lead cardiograms of case 22 illustrating the development of the RSR' pattern. (A) Embryonic $R$ wave in V1. (B) Secondary $R$ wave in $V 1$ and V4R. The time interval from the onset of the QRS complex to the peak of the embryonic $R$ wave in tracing (A) and of the secondary $R$ wave in tracing (B) is approximately the same $(0.05 \mathrm{sec}$.$) .$

and the third was an example of the pattern of right ventricular hypertrophy (Fig. 5). There was no good evidence that incomplete right bundle branch block contributed to the development of the RSR $^{\prime}$ pattern in these two cases, since no essential difference in timing was noted between the secondary $\mathbf{R}$ waves and the original embryonic $\mathrm{R}$ waves from which they appeared to grow.

The close relationship between the cardiographic picture of right ventricular hypertrophy and the RSR' pattern was further suggested in Case 20, Fig. 5. In serial graphs the mere disappearance of an initial $R$ wave in right chest leads, which occurred concurrently with the growth of an embryonic $R$ wave, changed the final picture from an $R_{S R}$ pattern to a $Q R$ pattern of right ventricular hypertrophy. Whether the presence or absence of an initial $R$ wave in $V 1$ is of sufficient functional :significance to warrant a different ætiology being assigned to these two cardiographic patterns, so strikingly similar in their progressive development, is questionable.

These theoretical considerations receive support in the high incidence of the RSR' pattern found in proven cases of right ventricular hypertension and hypertrophy. Myers et al. (1948) in an analysis of the cardiograms of forty cases of right ventricular hypertrophy, proven at autopsy, found ten examples of the RSR' pattern in addition to twenty showing the pattern of right ventricular hypertrophy. They considered that a persistent $\mathrm{RSR}^{\prime}$ pattern was suggestive, although not

* An embryonic $\mathbf{R}$ wave here denotes an upward deflection, the peak of which lies below or upon the isoelectric line 
21.3.49

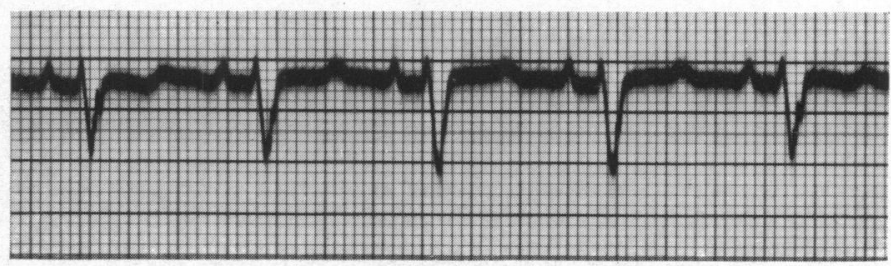

$\mathrm{A}-\mathrm{V} 1$

29.8.49

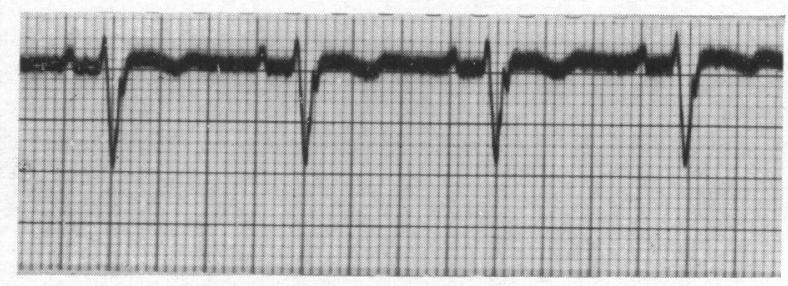

$\mathrm{B}-\mathrm{V} 1$

14.8 .51

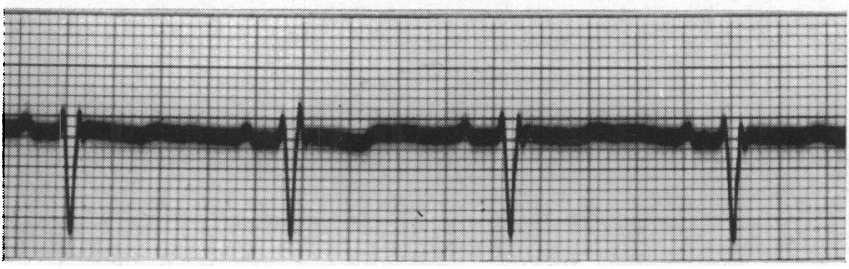

$\mathrm{C}-\mathrm{V} 1$

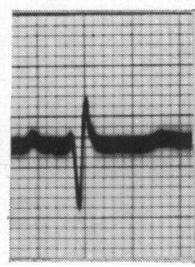

V4R

FIG. 4.-Selected chest lead cardiograms of case 8, illustrating the development of the RSR' pattern. (A) and (B) Small embryonic $R$ waves in V1. Their amplitude varies in phase with respiration. (C) Secondary $R$ wave in V1 and V4R. The time interval from the onset of the QRS complex to the peak of the embryonic $R$ wave in tracings (A) and (B) and of the secondary $R$ wave in tracing $(C)$ is approximately the same $(0.07 \mathrm{sec}$.$) .$

diagnostic, of right ventricular hypertrophy; they noted that it was usually transient when due to myocardial infarction or to pulmonary embolism. Johnson et al. (1950), in a series of forty cases of chronic pulmonary disease in whom right ventricular pressures had been measured, found seven examples of an RSR' pattern. Four of these had high mean pulmonary artery pressures, two had moderately raised pressures, and in only one was the pressure normal. In our series four cases out of sixteen showed this pattern at the time of catheterization and a fifth subsequently developed it. All five showed raised right ventricular systolic pressures in the absence of cardiac failure. A high incidence of the $\mathrm{RSR}^{\prime}$ pattern in chronic pulmonary heart disease has also been noted by Thomas (1948), Lavenne (1951), and Kilpatrick (1951).

It is not suggested that every case with an $\mathrm{RSR}^{\prime}$ pattern has right ventricular hypertrophy. Friedland et al. (1947) found right ventricular hypertrophy in only 70 per cent of a series of cases with such a pattern. An RSR' pattern is known to occur in normal hearts. But it would seem from the evidence presented that a persistent $\mathrm{RSR}^{\prime}$ pattern in cases of emphysema, is presumptive, although not pathognomonic, evidence of right ventricular hypertrophy. 


\section{2 .50}

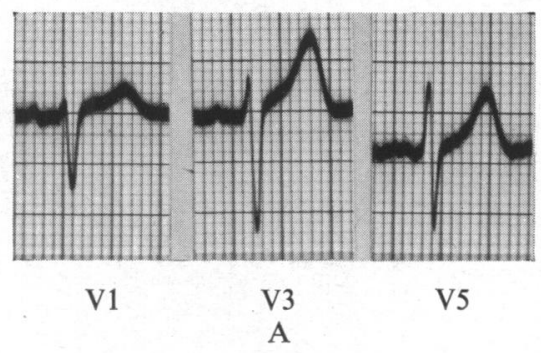

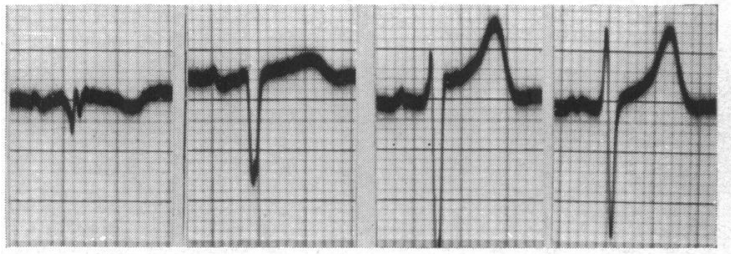

V4R

V1

V3

B

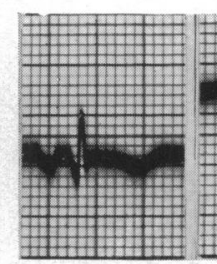

V4R

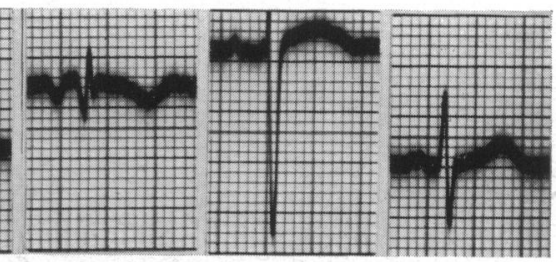

V1

C

(A) No embryonic $R$ wave in V1. (B) Embryonic $R$ wave in V1 and V4R. (C) Final R wave in V1 and V4R. The initial $R$ wave in $V 1$ seen in tracing $(A)$ has disappeared, with the resultant $Q R$ complex in tracing (C). The time interval from the onset of the $Q R S$ complex to the peak of the embryonic $R$ wave in tracing (B) and of the final $R$ wave in tracing $(C)$ is approximately the same $(0.05 \mathrm{sec}$.).

\section{Discussion}

\section{Relationship of Cardiogram to Right Ventricular Pressure}

The relationship between the cardiogram and resting right ventricular systolic pressure of patients not in failure was considered of interest since the findings of a raised pressure might be used as indirect evidence of right ventricular hypertrophy. It is likely that a greater degree or incidence of right ventricular hypertrophy may be found in patients with a sustained rise in resting right ventricular pressure when not in failure than in those in whom pulmonary hypertension is only intermittent. It will be seen from Fig. 6 that of the seven patients with resting right ventricular systolic pressures below $40 \mathrm{~mm}$. $\mathrm{Hg}$, six showed no cardiographic evidence of right ventricular hypertrophy while one had an $\mathrm{RSR}^{\prime}$ pattern, that was persistent. Of the nine patients with systolic pressures of $40 \mathrm{~mm}$. $\mathrm{Hg}$ and above, two had cardiographic evidence of right ventricular hypertrophy, three of a persistent RSR' pattern, one of complete right bundle branch block, and in three the cardiogram was normal. If a persistent $\mathrm{RSR}^{\prime}$ pattern in severe pulmonary emphysema be considered presumptive evidence of right ventricular hypertrophy, then some relationship is seen in the group as a whole between the cardiographic pattern and resting right ventricular systolic pressures in the absence of failure.

It will be noted, however, that the relationship was not a close one and that right ventricular hypertension occurred in some cases in the presence of a normal cardiogram. Cardiographic evidence of right ventricular hypertrophy, on the other hand, did not occur in the presence of a normal right ventricular pressure.

While our findings are in general agreement with those of Johnson et al. (1950), the two series cannot be very closely compared, since in their study the cardiograms were correlated with mean pulmonary artery pressures, as compared with systolic right ventricular pressures in our study ; 


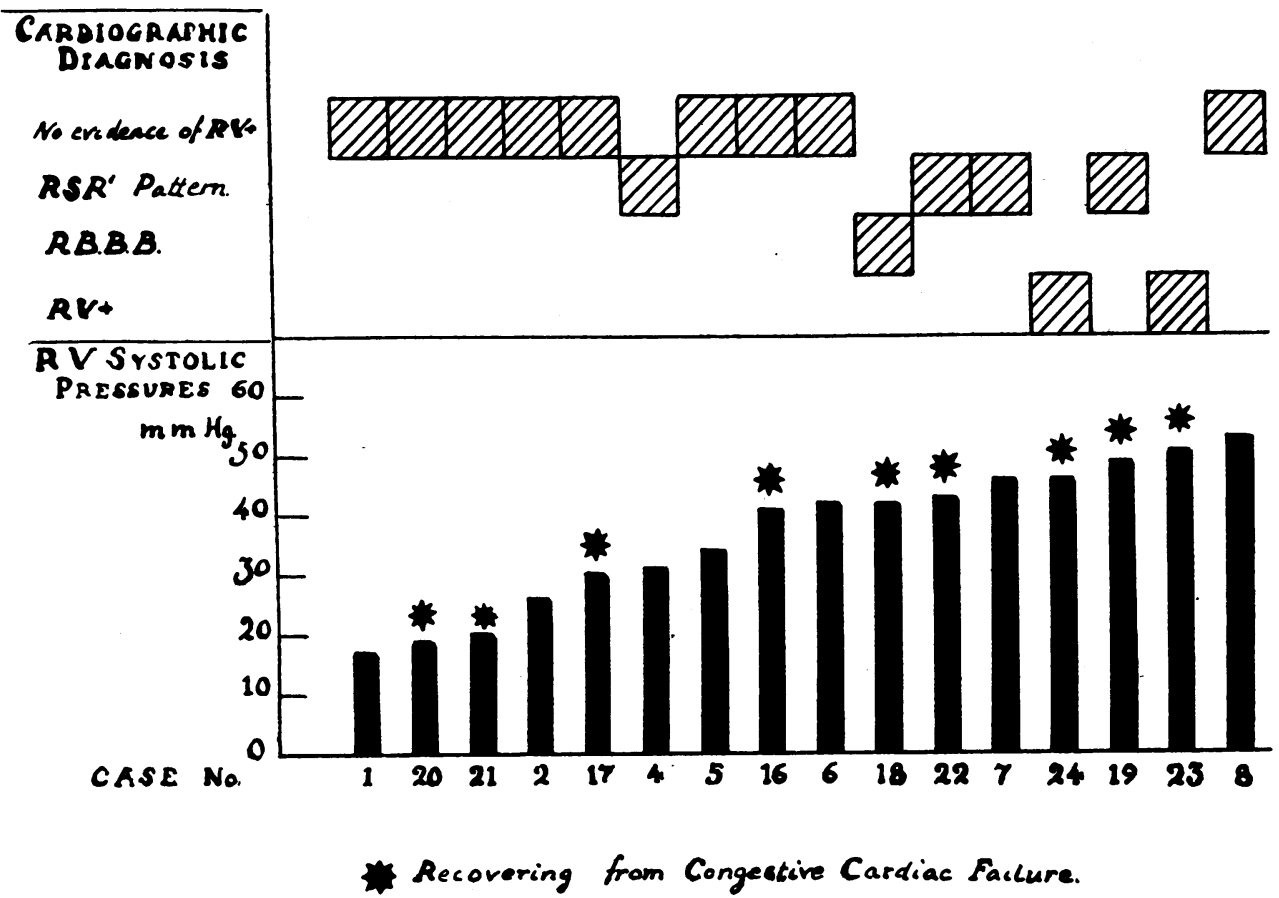

FIG. 6.-Relationship between the cardiogram and resting right ventricular systolic pressures of sixteen cases of severe pulmonary emphysema when not in cardiac failure.

in addition in some of their subjects in the high pressure group, the cardiograms were related only to the high pressures associated transiently with congestive heart failure. Similarly, close comparison of our findings to those of Kilpatrick (1951) is difficult, since he too used mean pulmonary arterial pressures (saline manometry) and did not distinguish between those patients who were and those who were not in congestive heart failure.

No immediate cardiographic alterations were found to accompany the marked fall in right ventricular systolic pressure, which was recorded on recovery from failure in the five patients in our series, in whom cardiac catheterization was repeated both in cardiac failure and on recovery from failure. In several of the patients, however, reported by Johnson et al. (1950), some cardiographic alterations did occur with the fall in mean pulmonary artery pressure on recovery from heart failure. In one case a QR pattern in V1 changed to an $\mathrm{RSR}^{\prime}$ pattern; simultaneously in lead V5 an RS changed to a QR pattern. These alterations were thought to be due to variations in the "electrical position" of the heart.

\section{Relationship of the Cardiogram to the Onset of Cardiac Failure}

In our series the onset of congestive failure anticipated the development of cardiographic evidence of right ventricular hypertrophy in five out of ten cases. The cardiogram remained negative in two out of four cases having a second attack of congestive failure. In one (Fig. 5), the cardiogram only became positive at the time of the seventh attack of cardiac failure over a period of twenty-one months. In two cases only did cardiographic evidence of right ventricular hypertrophy anticipate heart failure. It is therefore concluded that the development of cardiographic evidence of right ventricular hypertrophy may often be a late event in the clinical course of emphysema heart disease. 


\section{SUMMARY}

The cardiograms have been analysed in sixteen cases of severe pulmonary emphysema, in whom right ventricular pressures were measured. The cardiographic criteria for right ventricular hypertrophy have been based on those of Myers et al. (1948).

The genesis and possible significance of the RSR $^{\prime}$ pattern in right chest leads in emphysema have been discussed and previous studies have been briefly reviewed. It was concluded that a persistent $\mathrm{RSR}^{\prime}$ pattern in pulmonary emphysema was presumptive, although not diagnostic, evidence of right ventricular hypertrophy.

The relationship between the cardiographic pattern and right ventricular pressures has been examined. In the series as a whole, a relationship was seen between cardiographic evidence of right ventricular hypertrophy and increased resting right ventricular systolic pressure in the absence of congestive cardiac failure.

It was shown, however, that right ventricular hypertension could occur in the presence of a normal cardiogram, although cardiographic evidence of right ventricular hypertrophy was not found in the presence of a normal pressure.

The development of cardiographic evidence of right ventricular hypertrophy, as here defined, was often a relatively late event in the clinical course of emphysema heart disease. The value of the cardiogram, therefore, appeared to lie more in confirming the nature of the heart disease present than in diagnosing its inception.

We wish to acknowledge with sincere thanks the help of Professor J. McMichael, under whose guidance this study has been carried out, and the assistance of other members of the staff who performed some of the cardiac catheterizations. We are indebted to Dr. W. A. Briscoe and Dr. G. A. McLemore for kindly supplying us with the respiratory data.

\section{REFERENCES}

Bayliss, R. I. S., Etheridge, M. J., Hyman, A. L., Kelly, H. G., McMichael, J., and Reid, E. A. S. (1950). Brit. Heart J., $12,317$.

Borden, C. W., Wilson, R. H., Ebert, R. V., and Wells, H. S. (1950). Amer. J. Med., 8, 701.

Ferrer, M. I., Harvey, R. M., Cathcart, R. T., Webster, C. A., Richards, D. W., Jr., and Cournand, A.!(1950). Circulation, 1, 161.

Friedland, C., and Sodi-Pallares, D. (1947). Arch. Inst. Cardiol., Mexico, 17, 293.

Harvey, R. M., Ferrer, M. I., Richards, D. W. Jr., and Cournand, A. (1951). Amer. J. Med., 10, 719.

Johnson, J. B., Ferrer, M. I., West, J. R., and Cournand, A. (1950). Circulation, 1, 536.

Kilpatrick, J. A. (1951). Brit. Heart J., 13, 309.

Lavenne, F. (1951). Rev. belge. Path., 21, Suppl. 6.

Mounsey, J. P. D., Ritzmann, L. W., Selverstone, N. J., Briscoe, W. A., and McLemore, G. A. (1952). Brit. Heart J., $14,153$.

Myers, G. B., Klein, H. A., and Stofer, B. E. (1948). Amer. Heart J., 35, 1.

Thomas, A. J. (1948). Brit. Heart J., 10, 282.

Wilson, F. N., Rosenbaum, F. F., and Johnston, F. D. (1947). Advances in Internal Medicine. New York Interscience Publications, $2,1$. 